\title{
Fungos micorrízicos arbusculares de três espécies perenes de um Sistema Agroflorestal em Manaus (AM)
}

Os fungos micorrízicos arbusculares (FMAs) são seres simbiontes de solo que exercem um papel significativo na funcionalidade e manutenção dos ecossistemas naturais manejados e principalmente degradados. O presente estudo objetivou avaliar a ocorrência de FMAs na rizosfera de Andirobeira, Sapoteira do Solimões e Cupuaçuzei-ro presentes em um Sistema Agroflorestal, sendo avaliados em quatro meses (março, junho, setembro e dezembro) de 2018. 0 esquema fatorial $3 \times 4$ foi usado e as médias dos tratamentos foram comparadas pelo teste de Tukey. A ANOVA de medidas repetitivas demonstrou que há efeito do tempo (F ( 3,12$)$ $=3.776 ; p$ - valor $=0.019)$ e da interação entre tempo e espécie $(F(6,36)=3.918 ; p$-valor=0.004) na densidade de esporos. Verificou-se que as rizosferas da Sapoteira do Solimões e da Andirobeira apresentaram as maiores médias de densidade de esporos (76,2 e 70,4 esporos.50 g de solo-1), no mês de março encontrou-se uma amostra com 97 espo-ros.50 g de solo-1, sendo a maior encontrada. As maiores taxas de colonização micorrízica (\%) foram observadas nas rizosferas da Sapoteira do Solimões e da Andirobeira, as quais diferiram estatisticamente do Cupuaçuzeiro, não havendo diferença estatística entre os meses de coleta. 0 gênero Glomus spp. foi dominante nas rizosferas das plantas (43,1\%), sendo o menos abundante o Gigaspora spp. (10,04\%).

\section{Arbuscular mycorrhizal fungi of three perennial species from an Agroforestry System in Manaus (AM)}

\begin{abstract}
Arbuscular mycorrhizal fungi (AMFs) are symbiotic soil beings that play a significant role in the functionality and maintenance of managed and mainly degraded natural ecosystems. The present study aimed to evaluate the occurrence of AMFs in the rhizosphere of Andirobeira, Sapoteira do Solimões and Cupuaçuzei-ro present in an Agroforestry System, being evaluated in four months (March, June, September and December) of 2018. The 3×4 factorial scheme was used and the means of the treatments were compared by the Tukey test. The ANOVA of repetitive measures demonstrated that there is an effect of time $(F(3.12)=3.776 ; p-$ value $=0.019)$ and of the interaction between time and species $(F(6.36)=3,918 ; p$-value $=0.004)$ in spore density. It was found that the rhizospheres of Sapoteira do Solimões and Andirobeira had the highest mean spore density (76.2 and 70.4 spores.50 g of soil-1), in March a sample with 97 espo-ros.50 g of soil-1, the largest being found. The highest rates of mycorrhizal colonization (\%) were observed in the rhizospheres of Sapoteira do Solimões and Andirobeira, which differed statistically from Cupuaçuzeiro, with no statistical difference between the months of collection. The genus Glomus spp. was dominant in plant rhizospheres (43.1\%), the least abundant being Gigaspora spp. (10.04\%).
\end{abstract}

Keywords: Mycorrhizae; Agroforestry Systems; Amazon.

Topic: Microbiologia Agrícola e Ambiental

Reviewed anonymously in the process of blind peer.
Received: 02/02/2021

Approved: 26/02/2021
Lucas Henrique Oliveira

Instituto Nacional de Pesquisas da Amazônia, Brasil http://lattes.cnpq.br/1156112227811408

http://orcid.org/0000-0002-6429-8606

lucashenrique19915@gmail.com

Francisco Wesen Moreira (iD)

Instituto Nacional de Pesquisas da Amazônia, Brasil http://lattes.cnpq.br/1416538021119110

http://orcid.org/0000-0002-8763-254X

wesen@inpa.gov.br

Iokanam Sales Pereira (iD)

Instituto Nacional de Pesquisas da Amazônia, Brasil

http://lattes.cnpq.br/8866703199676448

http://orcid.org/0000-0001-8547-5061

iokanam.eng@gmail.com

\author{
Nailson Celso da Silva Nina \\ Instituto Federal do Amazonas, Brasil \\ http://lattes.cnpq.br/8956365866852696 \\ http://orcid.org/0000-0003-0971-4491 \\ ncsnina@gmail.com \\ Luiz Antonio de Oliveira (it \\ Instituto Nacional de Pesquisas da Amazônia, Brasil \\ http://lattes.cnpq.br/9931395111001102 \\ http://orcid.org/0000-0002-2008-7292 \\ luiz.oliveira@inpa.gov.br
}

Referencing this:

OLIVEIRA, L. H.; MOREIRA, F. W.; PEREIRA, I. S.; NINA, N. C. S.; OLIVEIRA, L. A.. Fungos micorrízicos arbusculares de três espécies perenes de um Sistema Agroflorestal em Manaus (AM). Revista Ibero Americana de Ciências Ambientais, v.12, n.2, p.148-157, 2021. DOI: http://doi.org/10.6008/CBPC2179-6858.2021.002.0015 


\section{INTRODUÇÃO}

Os microrganismos no solo interagem todo o tempo com as raízes das plantas, em um espaço denominado rizosfera. A atividade microbiana nos solos tropicais possui duas características tidas como os maiores exemplos do benefício dos microrganismos no desenvolvimento vegetal: a fixação biológica do nitrogênio e a formação de micorrizas (MOREIRA et al., 2006; MOREIRA et al., 2007; CHAGAS JUNIOR et al., 2010; CHAGNON et al., 2013).

Certos fungos do solo associam-se com as raízes de plantas vivas de forma simbiótica realizando transferências de água e nutrientes entre os simbiontes, estes são chamados de fungos micorrízicos (CARDOSO et al., 2016; BRUNDRETT et al., 2017). As micorrizas são interações simbióticas obrigatórias entre fungos micorrízicos e raízes de uma planta viva, são responsáveis pela transferência de nutrientes entre os simbiontes, planta hospedeira e fungo (BRUNDRETT, 2004).

Os fungos micorrízicos arbusculares (FMAs) são biotróficos obrigatórios, ou seja, dependem do seu hospedeiro vivo (HARLEY et al., 1983). São considerados como o tipo de fungo micorrízico mais comum, podendo ser encontrados em simbiose com aproximadamente $72 \%$ de todas as plantas vasculares (BRUNDRETT et al., 2017). Os FMAs são classificados taxonomicamente como pertencentes ao filo Glomeromycota, que atualmente possui 3 classes e 5 ordens 16 famílias, 42 gêneros e 305 espécies (TEDERSOO et al., 2018).

Os efeitos benéficos dos fungos micorrízicos arbuscularres (FMAs) no desempenho das plantas e na saúde do solo são essenciais para a gestão sustentável dos recursos agrícolas tendo papel fundamental na agroecologia (BERUDE et al., 2015). Segundo Costa et al. (2013) a utilização de sistemas agroflorestais (SAFs) como forma de cultivo favorece o aumento do número de esporos de FMAs no solo.

Apesar do registro da formação de micorrizas arbusculares em determinadas espécies arbóreas na região amazônica (ST. JOHN, 1980; OLIVEIRA et al., 2004; OLIVEIRA et al., 2005a; OLIVEIRA et al., 2010), ainda pouco se sabe sobre o efeito temporal do decorrer dos meses do ano na ocorrência de micorrizas arbusculares em plantas perenes de um SAF.

\section{MATERIAIS E MÉTODOS}

O estudo foi conduzido em um SAF, de aproximadamente 2,5 hectares, localizado no Instituto Federal do Amazonas (IFAM), Zona Leste de Manaus-AM. O clima predominante de Manaus é do tipo Af, segundo a classificação de Köppen, pertencendo ao grupo de clima tropical chuvoso (RIBEIRO, 1976; BASTOS, 1982). Na região predominam duas estações bem definidas, uma chuvosa e outra menos chuvosa, sendo a época mais seca entre os meses de agosto e setembro, quando a precipitação média mensal é cerca de 80 mm (ALVARES et al., 2013).

Com cerca de 65 espécies arbóreas o SAF localiza-se conforme as coordenadas S 5956'00.22" W 304'47.94". O solo da área estudada foi classificado como Latossolo Amarelo com textura variável de média a muito argilosa na área total (SCARAZATTI, 2011). 
Foram selecionadas para o estudo três espécies vegetais perenes do SAF, nativas do bioma Amazônico e com importância no mercado consumidor: Andirobeira (Carapa guianensis Aubl.), Cupuaçuzeiro (Theobroma grandiflorum K. Schum.) e Sapoteira-do-solimões (Quararibea cordata Vischer). Para cada espécie vegetal selecionou-se cinco árvores, como repetições, totalizando 15 indivíduos estudados.

As coletas foram realizadas no decorrer do ano de 2018 em intervalos trimestrais (março, junho, setembro e dezembro). As precipitações em cada mês de coleta se diferenciam pela variação pluviométrica durante o ano de 2018 (Fig.01).

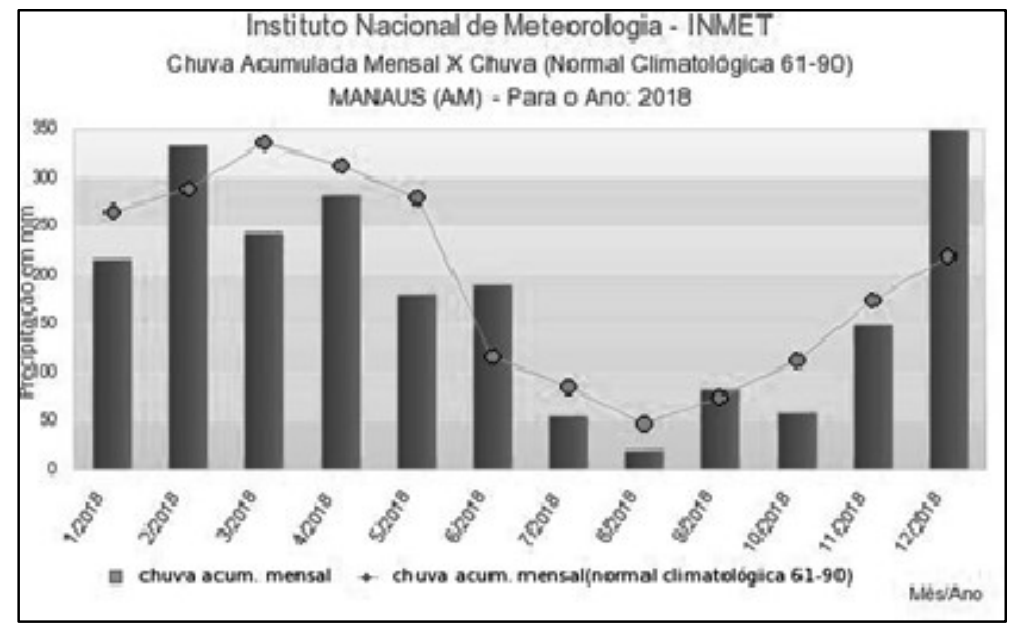

Figura 1: Precipitação acumulada mensal no ano de 2018 na cidade de Manaus-AM.

Foram coletadas 4 amostras de solo rizosférico de cada indivíduo, na projeção da copa, a uma profundidade de dez centímetros $(0-10 \mathrm{~cm})$, dando origem a uma amostra composta com aproximadamente $400 \mathrm{~g}$ por indivíduo.

Coletou-se também, na mesma sequência, as amostras de raízes finas da rizosfera de cada planta para as análises de colonização micorrízica. Usou-se a metodologia semelhante à descrita nos trabalhos de Oliveira et al. (1999; 2003) e Oliveira et al. (2004; 2005a; 2005b).

A extração dos esporos das amostras de solo foi realizada no Laboratório de Ecologia e Biotecnologia de Microrganismos da Amazônia - INPA (LEBMAM) utilizando a metodologia de extração por peneiramento úmido segundo Gerdemann et al. (1963).

Os esporos foram identificados em nível de gênero segundo Schenck et al. (1988). Para a identificação taxonômica utilizou-se as chaves especializadas de identificação contidas no banco de dados do International Culture Collection of Arbuscular and Vesicular-Arbuscular Mycorrhizal Fungi (INVAM) e do Guia Digital de Fungos Micorrízicos Arbusculares da Reserva Florestal Adolpho Ducke e Reserva do PDBFF (FREITAS et al., 2013).

Estimou-se também as variáveis de densidade de esporos (DE), de frequência de ocorrência (FO) e da abundância relativa (AR) de cada gênero de FMA (BROWER et al., 1984; MAGURRAN, 2004; DANDAN et al., 2007).

As amostras de raízes coletadas nas rizosferas passaram pelo procedimento de clareamento e coloração segundo a metodologia de Kormanick et al. (1980) para posteriormente serem observadas em 
microscópio as estruturas fúngicas características da associação, como os apressórios, arbúsculos, vesículas e hifas.

Tabela 1: Fórmulas descritivas das variáveis estimadas no estudo das micorrizas, segundo Brower et al. (1984); Magurran (2004).



Após o clareamento e coloração das raízes foi estimada a colonização micorrízica nas raízes das espécies vegetais. Foi empregado o "método da lâmina" segundo Giovannetti et al. (1980), o qual consistiu na montagem de lâminas com dez fragmentos de $1 \mathrm{~cm}$ de raízes finas.

Adotou-se o delineamento fatorial $3 \times 4$, onde os fatores representaram três espécies de plantas (andirobeira, sapoteira do solimões e cupuaçuzeiro) e quatro meses de coleta no ano de 2018 (março, junho, setembro e dezembro), com cinco repetições, totalizando 12 tratamentos com 60 unidades experimentais.

Para verificar as diferenças nas densidades de esporos em cada espécie ao longo do ano de 2018, foi realizada uma ANOVA de medidas repetidas (ANOVAREP). Para a análise das colonizações micorrízicas em cada espécie ao longo do ano de 2018, foi realizada uma ANOVA oneway.

Os resultados foram submetidos à aplicação do teste de normalidade (teste de Shapiro-Wilk) (SHAPIRO et al., 1965), avaliação da homocedasticidade (teste de Levene) e análise de variância empregandose o teste F. Constada a diferença entre os tratamentos foi realizado um teste de Tukey a $5 \%$ de probabilidade para comparação das médias dos tratamentos no programa estatístico SYSTAT 12.0.

\section{RESULTADOS E DISCUSSÃO}

A ANOVA de medidas repetitivas demonstrou que há efeito do tempo $(F(3,12)=3.776$; $p$ - valor= 0.019) e da interação entre tempo e espécie $(F(6,36)=3.918$; p-valor= 0.004) na densidade de esporos (Fig. 2). As comparações entre pares (post hoc de Bonferroni), mostraram que a densidade de esporos foi diferente somente entre o mês de setembro e dezembro ( $p$-valor=0.008).

No mês de setembro encontraram-se valores médios de densidade de esporos menores em relação aos demais meses. Tais meses apresentaram valores médios superiores, dando destaque para o mês de março que verificou uma variação média de 51-76,2 esporos em uma amostra de $50 \mathrm{~g}$ de solo. Quando se compara a densidade de esporos entre as espécies perenes avaliadas verifica-se que as rizosferas da Sapoteira do Solimões e da Andirobeira apresentaram as maiores médias (76,2 e 70,4 esporos.50 g de solo$\left.{ }^{1}\right)$.

A densidade de esporos encontrada na rizosfera do Cupuaçuzeiro variou de $27-69$ esporos.50 g de solo $^{-1}$, apresentando maiores esporulações nos meses de maior precipitação (março e dezembro). Em estudo 
semelhante, Oliveira et al. (2003) encontraram em diferentes meses de coleta nos anos de 1996 e 1997 uma média de 135 esporos/30g de solo na rizosfera de plantas de cupuaçu, sendo os maiores valores encontrados nos meses de maiores precipitações.

Outros estudos que avaliaram a esporulação em solos rizosféricos de Cupuaçuzeiros em SAFs (SILVA JUNIOR et al., 2006; FARIAS et al., 2015) apresentaram variação de 47-120 e 55-1075 esporos.50 g de solo-1, respectivamente.

O solo rizosférico da Sapoteira do Solimões mostrou um decréscimo na densidade de esporos no decorrer dos meses avaliados em 2018, tendo sua menor média no mês de setembro (32,5 esporos.50 g de solo $\left.^{-1}\right)$. Este fato pode estar relacionado com a baixa precipitação no mês de setembro de 2018.

O aumento na densidade de esporos em meses de maiores precipitações foi verificado por Nobre et al. (2010) em sistemas agroflorestais. De acordo com Oliveira et al. (2003), a alta esporulação em espécies florestais e a ausência de variação do número de esporos pode ser um indicativo da importância do uso de sistemas agroflorestais, onde favorece a esporulação durante o ano todo por conta da diversidade de espécies em um mesmo espaço, o que não ocorre em um monocultivo.

Estudos afirmam que a restrição de disponibilidade hídrica induz nos microrganismos associados à planta, a ativação de mecanismos de adaptação, como a elevação da esporulação (BONFIM et al., 2010), o que corrobora com os resultados encontrados na rizosfera da Andirobeira.

O mesmo foi confirmado por Caproni et al. (2007) em uma área revegetada após o uso de mineração no interior do Pará, onde observaram que a densidade de esporos aumentou no mês de período seco (agosto) em cultivos com Acacia holosericea A. Cunn. ex G. Don e Sesbania virgata (Cav.) Pers.

Existem muitos fatores que podem afetar a proliferação de esporos na rizosfera do hospedeiro, como a sazonalidade, os fatores edáficos, a dependência do hospedeiro, a idade das plantas hospedeiras, as habilidades de esporulação dos FMAs e os padrões de distribuição dos esporos de FMA nos solos (GEMMA et al., 1988; ABBOTT et al., 1991; ZHAO et al., 2001; Ll et al., 2007).

Os esporos de FMAs, também denominados de glomerosporos, foram identificados em nível de gênero. A diversidade de gêneros de FMAs nas rizosferas das espécies perenes inclui cinco principais gêneros (Acaulospora spp., Gigaspora spp., Glomus spp., Scutellospora spp., Entrosphospora spp.). Outros gêneros encontrados foram desconsiderados pelo irrisório número de esporos (Archeospora spp. e Diversispora spp.).

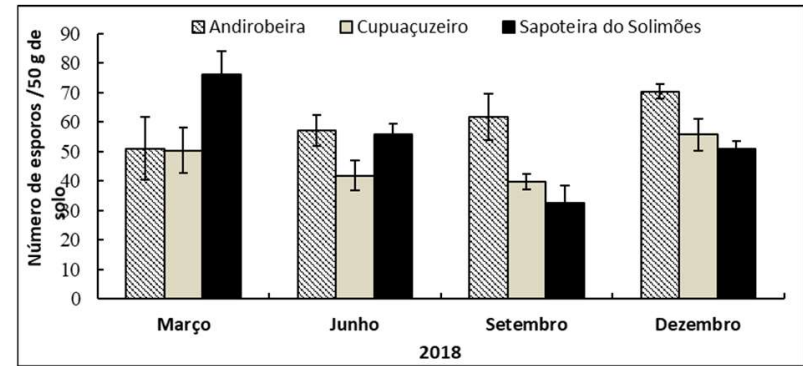

Figura 2: Gráfico da densidade de esporos de FMAs na rizosfera de três espécies perenes nos quatro meses de coleta, em um SAF de Manaus-AM. As barras representam os valores médios da densidade de esporos com seu devido erro padrão para cada mês (média \pm erro padrão).

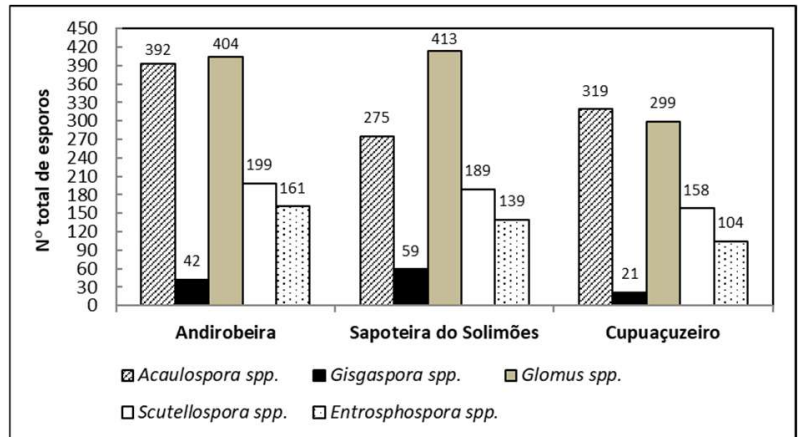

Figura 3: Número total de esporos encontrados em todas amostras das rizosferas das três espécies perenes do SAF, durante os meses avaliados de 2018. 
No total das amostras encontrou-se o maior número total de esporos a rizosfera da Andirobeira (1198) em relação às outras espécies perenes (Sapoteira do Solimões - 1075, Cupuaçuzeiro - 901), dando destaque para os gêneros Acaulospora spp. (392) e Glomus spp. (404), figura 3.

Em estudo realizado na Amazônia em área de floresta nativa, Freitas et al. (2013) relataram que 44\% do total dos gêneros identificados pertenciam aos gêneros Acaulospora spp. e Glomus spp..

Silva Junior et al. (2006) estudando as comunidades de FMAs associadas à pupunha e ao cupuaçu, em sistema agroflorestal e em monocultivo na Amazônia Central reportaram os gêneros Acaulospora spp. e Glomus spp. como os mais frequentes, confirmando os resultados encontrados neste estudo. De acordo com Loss et al. (2009) os gêneros Acaulospora spp. e Glomus spp. demonstram ser resistentes em áreas com perturbações ambientais.

A ocorrência destes gêneros pode estar condicionada a variáveis edáficas da área, como pH, teores de matéria orgânica e disponibilidade de $\mathrm{P}, \mathrm{Ca}$ e $\mathrm{Mg}$, os quais influenciam na sua ocorrência, germinação e colonização de plantas (SIQUEIRA et al., 2010; LOSS et al., 2009; NOBRE et al., 2010).

A rizosfera da Sapoteira do Solimões apresentou 413 esporos do gênero Glomus spp., sugerindo uma alta afinidade fungo-planta entre estes simbiontes nas condições edafoclimáticas locais.

O gênero Gigaspora spp. apresentou os menores números de esporos em relação aos demais gêneros de FMAs, nas rizosferas das três espécies vegetais perenes (Fig.03).

A abundância relativa dos gêneros de FMA mostraram que o Glomus spp. foi dominante nas rizosferas das plantas (43,1\%), seguido dos gêneros Acaulospora spp. (39,7\%), Scutellospora spp. (20,98 \%), Entrosphospora spp. (17,48 \%) e Gigaspora spp. (10,04 \%) (Tabela 02).

Nas rizosferas das três espécies o gênero Gigaspora spp. foi o que apresentou menores valores de abundância relativa, mostrando que esse gênero apresentou baixa esporulação no SAF estudado. O gênero Acaulospora spp. mostrou maior abundância no mês de setembro nas rizosferas das três espécies perenes, mês que se caracteriza com baixo índice pluviométrico na região de Manaus-AM. Já os gêneros Scutellospora spp. e Entrosphospora spp. mostraram ser mais abundantes no mês de junho.

Tabela 2: Abundância relativa (AR) e Frequência de ocorrência (FO) dos gêneros de FMAs encontrados na rizosfera de três espécies perenes em quatro épocas de coleta do ano de 2018.

\begin{tabular}{|c|c|c|c|c|c|c|}
\hline & & AR (\%) & & & & \\
\hline Espécies & $\begin{array}{l}\text { Meses de } \\
\text { coleta }\end{array}$ & Acaulospora spp. & Entrosphospora spp. & Gisgaspora spp. & Glomus spp. & Scutellospora spp. \\
\hline \multirow{4}{*}{ Andir. } & Mar/2018 & 31,76 & 8,24 & 3,92 & 37,25 & 18,43 \\
\hline & Jun/2018 & 29,02 & 17,48 & 1,40 & 30,77 & 20,98 \\
\hline & Set/2018 & 38,31 & 12,34 & 1,95 & 30,52 & 16,56 \\
\hline & Dez/2018 & 31,25 & 14,77 & 6,25 & 36,08 & 11,65 \\
\hline \multirow{4}{*}{ Sapot. } & Mar/2018 & 28,35 & 9,97 & 4,46 & 43,31 & 13,39 \\
\hline & Jun/2018 & 17,92 & 16,85 & 10,04 & 34,05 & 21,15 \\
\hline & Set/2018 & 30,06 & 11,04 & 1,84 & 39,26 & 17,79 \\
\hline & Dez/2018 & 26,77 & 14,17 & 4,33 & 35,04 & 19,69 \\
\hline \multirow{4}{*}{ Cupu. } & Mar/2018 & 37,27 & 10,91 & 3,64 & 27,27 & 19,55 \\
\hline & Jun/2018 & 27,75 & 11,96 & 2,39 & 37,80 & 19,62 \\
\hline & Set/2018 & 39,70 & 13,07 & 1,51 & 28,64 & 17,09 \\
\hline & Dez/2018 & 35,84 & 10,39 & 1,79 & 36,92 & 14,34 \\
\hline $\mathrm{FO}(\%)$ & & 100 & 100 & 76,7 & 100 & 100 \\
\hline
\end{tabular}


Stürmer et al. (2011) estudando a distribuição de FMAs em distintos usos da terra na Amazônia relataram maiores índices de abundância relativa para o gênero Acaulospora spp. (55\%) em sistemas agroflorestais.

Também na Amazônia, Miranda et al. (2010) avaliando comunidades de fungos micorrízicos arbusculares associados ao amendoim forrageiro observaram que a espécie Glomus macrocarpum foi a de maior abundância relativa nas duas estações avaliadas (71,3 \% e 76 \%).

Quanto à frequência de ocorrência (FO), quatro dos cinco gêneros de FMAs encontrados foram $100 \%$ frequentes nas amostras avaliadas, divergindo do restante somente o gênero Gigaspora spp. com 76,7 \% de frequência de ocorrência.

Segundo Dandan et al. (2007), a frequência de ocorrência é definida como a porcentagem de amostras de solo em que um gênero ou espécie ocorreu. Em um estudo de uma área de plantio misto de espécies arbóreas na Amazônia Caproni et al. (2007) verificaram que as espécies do gênero Glomus spp. foram mais frequentes nos dois meses avaliados (agosto/1998 e abril/1999).

Segundo Corrêa et al. (2013) o gênero de FMAs Glomus spp. apresentou ampla adaptação à variação ambiental em ambos os sistemas de cultivo estudados (Monocultura e Sistemas Agroflorestais) na Amazônia. Silva Junior et al. (2006) confirma que o gênero Glomus spp. possui vasta distribuição na zona tropical.

Quanto a colonização micorrízica a Sapoteira do Solimões foi a espécie mais colonizada por FMAs $(38,25 \%)$ no presente estudo, diferindo estatisticamente do Cupuaçuzeiro que teve a menor média (18,75 \%) (Tab. 03).

Tabela 3: Colonização total (hifas, vesículas, esporos e arbúsculos) por FMAs em espécies perenes em quatro épocas de coleta do ano de 2018. Médias seguidas da mesma letra minúscula na linha e maiúsculas nas colunas não diferem entre si pelo Teste de Tukey a $5 \%$.

\begin{tabular}{|c|c|c|c|c|c|}
\hline \multirow{2}{*}{ Espéc. } & \multicolumn{5}{|c|}{ Meses de coleta de 2018} \\
\hline & Mar & Jun & Set & Dez & Médias \\
\hline Andir. & $23 \mathrm{aA}$ & $42 \mathrm{aA}$ & $22 \mathrm{aA}$ & $43 a A$ & $32,5 \mathrm{~A}$ \\
\hline Sapot. & $47 \mathrm{aA}$ & $40 \mathrm{aA}$ & $44 \mathrm{aA}$ & $22 \mathrm{aA}$ & $38,2 \mathrm{~A}$ \\
\hline Cupu. & $16 \mathrm{aB}$ & $22 \mathrm{aB}$ & $11 \mathrm{aB}$ & $26 \mathrm{aB}$ & $18,7 \mathrm{~B}$ \\
\hline Médias & $28,7 \mathrm{a}$ & $34,7 a$ & $25,7 \mathrm{a}$ & 30,3 a & \\
\hline
\end{tabular}

A análise de variância mostrou que houve diferença significativa entre as espécies, os valores médios de colonização micorrízica de Cupuaçuzeiro diferenciaram significativamente entre as demais espécies perenes em todos os meses de coleta, apresentando os menores valores de colonização micorrízica (16 - 26 \%). Percebe-se que a colonização micorrízica arbuscular variou entre os meses de coleta, mesmo não diferindo significativamente entre si. No mês de dezembro a Andirobeira e Cupuaçuzeiro apresentaram suas taxas de colonização máximas (43 \% e 26 \%). Neste mesmo mês de coleta a Sapoteira do Solimões apresentou sua taxa mínima de colonização micorrízica (22\%).

Resultados semelhantes foram observados por Silva Junior et al. (2006) quando obtiveram uma maior taxa de colonização do Cupuaçuzeiro no período chuvoso (21,93\%) em monocultivo, confirmando parcialmente ao encontrado no presente estudo para a mesma espécie perene (26\%) no mês de dezembro que apresenta alta precipitação na região Amazônica. 
O fato da alta colonização de micorrízica encontrada na Sapoteira do Solimões pode ser devido à maior quantidade de serapilheira na superfície do solo em relação às outras espécies, tendo consequentemente maiores teores de matéria orgânica, o que induz a atividade microbiana do solo.

No mês de junho houve a maior média de colonização micorrízica $(34,7 \%)$, um mês de baixa pluviosidade. A maior colonização micorrízica em meses de baixa pluviosidade do ano foi relatada por vários autores (OLIVEIRA et al., 2005b; NOBRE et al., 2010; TEIXEIRA-RIOS et al., 2018).

Os maiores valores de colonização se referem às hifas, fundamentais para o estabelecimento das associações micorrízicas entre fungo e planta, sendo a estrutura micorrízica mais determinante na obtenção do valor da colonização total.

\section{CONCLUSÕES}

Diante dos resultados alcançados no estudo concluiu-se que há influência das rizosferas das espécies perenes e dos meses de coleta nas presenças de esporos nas rizosferas das plantas.

A densidade de esporos de FMAs variou significativamente entre as espécies perenes e entre os meses de coleta em 2018. Foram encontradas as maiores esporulações nas rizosferas de Andirobeira e Sapoteira do Solimões. As maiores densidades de esporos foram nos meses de março e dezembro, típicos meses de maior precipitação na Amazônia.

Foi observada maior abundância relativa do gênero Glomus spp., dominante nas rizosferas das plantas estudadas. Os valores de colonização micorrízica total demonstraram diferença significativa entre as espécies perenes, no qual o Cupuaçuzeiro diferiu das demais espécies, apresentando os menores valores de colonização.

AGRADECIMENTOS: Ao Conselho Científico de Desenvolvimento Científico e Tecnológico (CNPq) e Coordenação de Aperfeiçoamento de Pessoal de Nível Superior (CAPES) pelo apoio financeiro para a realização dessa pesquisa.

\section{REFERÊNCIAS}

ABBOTT, L. K.; ROBSON, A. D.. Factors influencing the occurrence of vesicular arbuscular mycorrhizas. Agriculture, Ecosystems and Environment, v.35, p.121-150, 1991.

ALVARES, C. A.; STAPE, J. L.; SENTELHAS, P. C.; GONÇALVES, J. L. M.; SPAROVEK, G.. Köppen's climate classification map for Brazil. Meteorologische Zeitschrift, v.22, p.711-728, 2013.

BERUDE, M. C.; ALMEIDA, D. S.; RIVA, M. M.; CABANÊZ, P. A.; AMARAL, A. A.. Micorrizas e sua importância agroecológica. Enciclopédia Biosfera, v.11, n.22, p.132, 2015.

BONFIM, J. A.; MATSUMOTO, S. N.; LIMA, J. M.; CÉSAR, F. R. C. F.; SANTOS, M. A. F.. Fungos micorrízicos arbusculares (FMA) e aspectos fisiológicos em cafeeiros cultivados em sistema agroflorestal e a pleno sol. Bragantia, Campinas, v.69, n.1, p.201-206, 2010. DOI:

https://doi.org/10.1590/S0006-87052010000100025

BROWER, J. E.; ZAR, J. H.; VON ENDE, C. N.. Field and laboratory methods for general ecology. Dubuque: William C. Brown, 1984.

BRUNDRETT, M. C.. Diversity and classification of mycorrhizal associations. Biological Reviews, v.79, p.473495, 2004.

BRUNDRETT, M. C.; TEDERSOO, L.. Evolutionary history of mycorrhizal symbioses and global host plant diversity. New Phytologist, v.220, p.1108-1115, 2017. DOI: http://doi.org/10.1111/nph.14976

CAPRONI, A. L.; FRANCO, A. A.; GRANHA, J. D. O.; SOUCHIE, E. L.. Ocorrência de Fungos Micorrízicos Arbusculares em 
resíduo da mineração de bauxita revegetado com espécies arbóreas. Acta Botanica Brasílica, v.21, n.1, p.99-106, 2007.

CARDOSO, E. J. B. N.; ANDREOTE, F. D.. Microbiologia do solo. 2 ed. Piracicaba: ESALQ, 2016

CORRÊA, H. S.; KNOECHELMANN, C. M.; MELLO, H. A.; PEREIRA, F. D.; MICHELOTTI, F.; MANESCHY, R. Q.. Fungos micorrízicos arbusculares associados às culturas cultivadas em sistemas agroflorestais e em monoculturas em projetos de assentamento do sudeste paraense. Revista Agroecossistemas, v.2, n.1, p.13-17, 2013.

COSTA, J. R.; MORAIS, R. R.. Carapa guianensis Aubl. (Andirobeira) em sistemas agroflorestais. Embrapa Amazônia Ocidental-Documentos. Manaus: EMBRAPA, 2013.

CHAGNON, P. L.; BRADLEY, R. L.; MAHERALI, H.; KLIRONOMO, J. N.. A trait-based framework to understand life history of mycorrhizal fungi. Trends in Plant Science, v.18, p.484-491, 2013

DANDAN, Z.; ZHIWEI, Z.. Biodiversity of arbuscular mycorrhizal fungi in the hot-dry valley of the Jinsha River, southwest China. Applied Soil Ecology, v.37, n.1-2, p.118128, 2007.

FARIAS, E.; SILVA, J. V.; LIMA, H. E.; SILVA, K.. Densidade e diversidade de fungos micorrízicos arbusculares em solos próximos a raízes de cupuaçuzeiro em um sistema agroflorestal de Roraima. In: CONGRESSO BRASILEIRO DE CIÊNCIA DO SOLO, 35. Anais. Natal: Sociedade Brasileira de Ciência do Solo, 2015.

FREITAS, R. O.; CARRENHO, R.. Guia Digital de Fungos Micorrízicos Arbusculares da Reserva Florestal Adolpho Ducke e Reserva do PDBFF. Manaus: INPA, 2013.

GEMMA, J. N.; KOSKE, R. E.. Seasonal variation in spore abundance and dormancy of Gigaspora gigantea and in mycorrhizal inoculum potential of a dune soil. Mycologia, v.80, n.2, p.211-216, 1988.

GERDEMANN, J. W.; NICOLSON, T. H.. Spores of mycorrhizal Endogone species extracted from soil by wet sieving and decating. Trans. Br. Mycol. Soc., v.46, p.235-244, 1963.

GIOVANNETTI, M.; MOSSE, B.. An evaluation of techniques for measuring vesicular arbuscular mycorrhizal infection in roots. New Phytologist, v.84, p.489-500, 1980.

HARLEY, J. L.; SMITH, S. E.. Mycorrhizal symbiosis. London: Academic Press, 1983.

KORMANICK, P. P.; BRYAN, W. C.; SCHULTZ, R. C.. Procedures and equipament for staining large numbers of plant root samples for endomycorrhizal assay. Can. J. Microbiol., v.26, p.536-538, 1980.

LOSS, A.; ANGELINI, G. A. R.; PEREIRA, A. C. C.; LÃ, O. R.; MAGALHÃES, M. O. L.; SILVA, E. M. R.; JUNIOR, O. J. S.. Atributos químicos do solo e ocorrência de fungos micorrízicos sob áreas de pastagem e sistema agroflorestal, Brasil. Acta Agronómica, v.58, n.2, p.91-95, 2009.

LI, L. F.; ZHANG, Y.; ZHAO, Z. W.. Arbuscular mycorrhizal colonization and spore density across different land-use types in a hot and arid ecosystem, Southwest China. Journal of Plant Nutrition and Soil Science, v.170, n.3, p.419-425, 2007.

MAGURRAN, A. E.. Measuring biological diversity blackwell science. In: Biological Diversity: Frontiers in Measurement and Assessment. Oxford, 2004.

MIRANDA, E. M.; SILVA, E. M. R.; SAGGIN JUNIOR, O. J.. Comunidades de fungos micorrízicos arbusculares associados ao amendoim forrageiro em pastagens consorciadas no Estado do Acre, Brasil. Embrapa AcreArtigo em periódico indexado, 2010.

MOREIRA, F. M. S.; SIQUEIRA, J. O.. Microbiologia e bioquímica do solo. Lavras: UFLA, 2006.

MOREIRA, M.; BARETTA, D.; TSAI, S. M.; COSTA, S. M. G.; CARDOSO, E. J. B. N.. Biodiversity and distribution of arbuscular mycorrhizal fungi in Araucaria forest. Scientia Agrícola, Piracicaba, v.64, p.393-399, 2007.

NOBRE, C. P.; JÚNIOR, A. S. D. L. F.; GOTO, B. T.; BERBARA, R. L. L.; NOGUEIRA, M. D. C.. Fungos micorrízicos arbusculares em sistema de aléias no Estado do Maranhão, Brasil. Acta Amazonica, v.40, n.4, 2010

OLIVEIRA, A. N.; OLIVEIRA, L. A.. Associação micorrízica e teores de nutrientes nas folhas de cupuaçuzeiro (Theobroma grandiflorum) e guaranazeiro (Paullinia cupana) de um sistema agroflorestal em Manaus, Amazonas. Revista Brasileira de Ciência do Solo, v.28, p.1063-1068, 2004

OLIVEIRA, A. N.; OLIVEIRA, L. A.. Colonização por fungos micorrízicos arbusculares e teores de nutrientes em cinco cultivares de bananeiras em um latossolo da Amazônia. Revista Brasileira de Ciências do Solo, v.29, p.481-488, 2005a.

OLIVEIRA, A. N.; OLIVEIRA, L. A.. Seasonal dynamics of arbuscular mycorrhizal fungi in plants of Theobroma grandiflorum Schumand Paullinia cupana Mart. Of an agroforestry system in Central Amazônia, Amazonas state, Brazil. Brazilian Journal of Microbiology, v.36, p.262-270, 2005b.

OLIVEIRA, A. N.; OLIVEIRA, L. A.. Sazonalidade, colonização radicular e esporulação de fungos micorrízicos arbusculares em plantas de cupuaçuzeiro e de pupunheira na Amazônia Central. Revista Ciências Agrárias, v.40, p.145-154, 2003.

OLIVEIRA, L. A.; GUITTON, T. L.; MOREIRA, F. W.. Relações entre as colonizações por fungos micorrízicos arbusculares e teores de nutrientes foliares em oito espécies florestais da Amazônia. Acta Amazônica, v.29, p.183-193, 1999.

RIBEIRO, M. N. G.. Aspectos climatológicos de Manaus. Acta Amazônica, v.6, p.229-233, 1976.

SCARAZATTI, B.. Sistema Agroflorestal como alternativa de uso da terra: um estudo de caso na Unidade Demonstrativa de Permacultura (UDP) de Manaus/AM. Dissertação (Mestrado) - Instituto Nacional de Pesquisas da Amazônia, Manaus, 2011. 
SCHENCK, N. C.; PEREZ, Y.. Manual for identification of vesicular arbuscular mycorrhizal fungi. Gainesville: INVAM, 1988.

SHAPIRO, S. S.; WILK, M. B.. An analysis of variance test for normality (complete samples). Biometrika, v.52, p.591-611, 1965.

SILVA JUNIOR, J. P.; CARDOSO, E. J. B. N.. Micorriza arbuscular em cupuaçu e pupunha cultivados em sistema agroflorestal e em monocultivo na Amazônia Central.

Pesquisa Agropecuária Brasileira, v.41, p.819-825, 2006.

SIQUEIRA, J. O.; SOUZA, F. A.; CARDOSO, E. J. B. N.; TSAI, S. M.. Micorrizas: 30 anos de pesquisa no Brasil. Lavras: UFLA, 2010.

STÜRMER, S. L.; SIQUEIRA, J. O.. Species richness and spore abundance of arbuscular mycorrhizal fungi across distinct land uses in Western Brazilian Amazon. Mycorrhiza, v.21, n.4, p.255-267, 2011.

ST. JOHN, T. V.. A survey of micorrhizal infection in an Amazonian rain forest. Acta Amazônica, v.3, p.527-533, 1980.

TEDERSOO, L.; RAMÍREZ, S. S.; KÕLALG, U.; BAHRAM, M.; DORING, M.; SCHIGEL, D.; MAY, T.; RYBERG, M.;

ABARENKOV, K.. High-level classification of the Fungi and a tool for evolutionary ecological analyses. Fungal Diversity, v.90, p.135-159, 2018.

TEIXEIRA-RIOS, T.; SILVA, D. K. A.; GOTO, B. T.; YANO-MELO, A. M.. Seasonal differences in arbuscular mycorrhizal fungal communities in two woody species dominating semiarid caatinga forests. Folia Geobotanica, v.53, n.2, p.191-200, 2018.

A CBPC - Companhia Brasileira de Produção Científica (CNPJ: 11.221.422/0001-03) detém os direitos materiais desta publicação. Os direitos referem-se à publicação do trabalho em qualquer parte do mundo, incluindo os direitos às renovações, expansões e disseminações da contribuição, bem como outros direitos subsidiários. Todos os trabalhos publicados eletronicamente poderão posteriormente ser publicados em coletâneas impressas sob coordenação da Sustenere Publishing, da Companhia Brasileira de Produção Científica e seus parceiros autorizados. Os (as) autores (as) preservam os direitos autorais, mas não têm permissão para a publicação da contribuição em outro meio, impresso ou digital, em português ou em tradução. 